\title{
The Model of Teachers' Roles in Promoting Learner Autonomy Based on Ubiquitous Computing Technologies
}

\author{
Huanhuan $\operatorname{Ren}^{1, a}$, Chi Ma ${ }^{2, b}$ \\ ${ }^{1}$ Teachign and Research Institute of Foreign Languages, Bohai University, Jinzhou 121013, China; \\ ${ }^{2}$ Jinzhou Institute of Forestry Research, Jinzhou Forestry Bureau, Jinzhou 121013, China. \\ arenhuanhuan2014@163.com, 'bmachi2014@tom.com
}

Keywords: Model of teachers' roles, learner autonomy, ubiquitous computing technologies.

\begin{abstract}
The promotion of learner autonomy in ubiquitous network environment is dependent greatly on how teachers are aware of their new roles through the use of ubiquitous computing technologies. It's shown that roles teachers play in ubiquitous learning space should shift to less control on learning and more concern on learners. Concrete suggestions on teachers' roles are proposed regarding teachers as idea champion, personal coach, active impetus, feedback provider and information source in ubiquitous network environment. It's hoped that the benefits of learner autonomy may accrue whilst teachers play appropriate and supportive roles in ubiquitous learning space.
\end{abstract}

\section{Introduction}

The promotion of learner autonomy in ubiquitous network environment is dependent greatly on how teachers are aware of their new roles. Teachers are required to change their roles so as to adapt themselves to the new requirement of autonomy. This paper aims at exploring the model of teachers' roles in promoting learner autonomy based on ubiquitous computing technologies. It proposes to clarify the importance of learner autonomy and its implication, a critical review about teachers' roles and concrete suggestions on teachers' roles in ubiquitous learning space, so that learner autonomy of each person can be promoted and fostered in ubiquitous network environment.

\section{Literature Reviews on Learner Autonomy and Its Implication}

Theoretical Sources of Learner Autonomy. Learner autonomy is not an isolated theory as a complex of theories have influenced and fostered learner autonomy. Learner autonomy has its roots in philosophy which regards teaching as a means of not teaching. The objective of teaching is to enable learners with the ability to learn themselves. Learner autonomy also confirms with the theory of constructivism, calling for teachers to understand the steps in the development of the child's mind. According to Piaget, knowledge is constructed by learners through making meaning in relation to the interaction between their experiences and their ideas[1]. Constructivism values an active, mental process of development of learners. Lastly, the theory of humanism provides favorable theoretical support for learner autonomy by providing an outlook or even way of life centered on human need and interest[2]. In a word, current literature implies that learner autonomy puts a multi-disciplinary approach to current educational research and practice.

Characteristics of Learner Autonomy. It is clear that there is a general vibe about what constitutes learner autonomy, despite the lack of a specific and uniform definition[3]. A hybrid of characteristics and features of a successful autonomous learner can be listed even if autonomous learners are different in a number of ways. According to Holec, learners qualify as autonomous learners when they independently choose aims and purposes and set goals; choose materials, method and tasks; exercise choice and purpose in organizing and carrying out the chosen tasks; and choose criteria for evaluation[4]. In Nuan's study, it's shown that, the characteristics of an autonomous learner can be identified as a diversity of skills, passion and enjoyment for a particular field, a focused 
and active approach to learning, and finally, pursuit of learning and success despite high probability of failure and public disapproval[5]. From above, we can see learners becomes autonomous learners as they assume more responsibilities for their learning and make more choices about what they learn and how we learn.

Teacher Instruction and Learner Autonomy. A few things may come easily to learners but learner autonomy arrives after efforts. The vast majority of students do not possess the motivation nor ambition to become autonomous learners. It's found that learner autonomy is not born, rather is cultivated by factors from multiple forces. The value of the teacher in promoting autonomous learning through a blended teaching approach cannot be underestimated. To be in tune with the essence of learner autonomy, teachers are suggested to strike to build a nurturing and supportive learning environment, as the cultivation of learner autonomy can't be separated from establishing a good learning environment. Learners are encouraged to explore and seek assistance from teachers and other agents in the learning environment. Teachers play a prominent role in developing learners' ability of taking charge of themselves and taking informed action in their learning process. All in all, it confirmed that teacher instruction can find its way in fostering learner autonomy in ubiquitous learning space.

\section{Critical Analysis of Teachers' Roles in Promoting Learner Autonomy Based on Ubiquitous Computing Technologies}

Less Control on Learning in Ubiquitous Learning. Learner autonomy requires teachers to make shift from more intervention to less control in learning process. Learners are the builders and creators of meaning and knowledge, and they should take initiative to make decision, engage with learning and adjust to learning environment. However, the raising of learner autonomy in the past was not always joy and fun. The teaching paradigm grounded heavily in the teacher-centered concept emphasizes on more control on learners. Students are passive absorbers of information and they are more likely to be at lost in the teacher-centered learning mode. And it doesn't conform with the idea of learner autonomy. It's wise for learners to adapt themselves to new requirement of autonomy, especially with the aid of ubiquitous computing technologies. The power of learning should be transferred to learners who are encouraged to be equipped with the ability to leverage enabling technologies so as to get the greatest freedom and potential in ubiquitous learning space.

More Concern on Learners in Ubiquitous Learning. Autonomous learning does not simply mean learning by oneself and it entails assistance from the teacher side. But one commonly asked question is: how will the teacher be needed if students become completely autonomous? And one thing is the concern on learners, which hasn't so far draw much concern of teachers. For so long time, learners haven't paid close attention to the overall development of learners, not alone the notice of inner world of each student. It's true that the learning situations in few regions may not be the norm. Then it's wise for learners to put more stress on learners as opposed to final scores achieved by learners, since the learners account much more than the learning outcomes. It's especially true in ubiquitous learning space, as it's more convenient and easier for teachers to get in touch with learners and talk about learning. In brief, the frequent emergence of new methodologies and technologies is more likely to give rise to the development of learner autonomy through keeping an watchful eye on learners .

\section{Concrete Suggestions on Teachers' Roles in Promoting Learner Autonomy Based on Ubiquitous Computing Technologies}

Teachers' Role as Idea Champion in Ubiquitous Learning Space. There is some truth about the idea that much can be learned in ubiquitous learning space, but the knowledge about learner autonomy is more likely to be underestimated by learners in the process of ubiquitous learning. No matter how evolutionary and powerful technologies become applied in the educational domain, one important component behind successful learning is something related to education. In other words, 
only learners are savvy about how to learn, can learners avail themselves of computing technologies for better learning outcomes. Therefore, it's very important for learners to be informed about why and how to be autonomous learners. It should be articulated by teachers in any way that the impact of learner autonomy on learners are profound and far-reaching, as it's not only an once-for-all choice, but it's also a lifelong endeavor. How then does one instill this idea of autonomous learning in learners that are not naturally predisposed to the skill set? It accounts on teachers too. In this regard, the role of teachers as idea champions in learner autonomy is absolutely vital as they equip learners with the ability to learn before learning, and trigger ideas, decision and reflection of learners about learning process in ubiquitous network environment.

\section{ACTIVE IMPETUS}

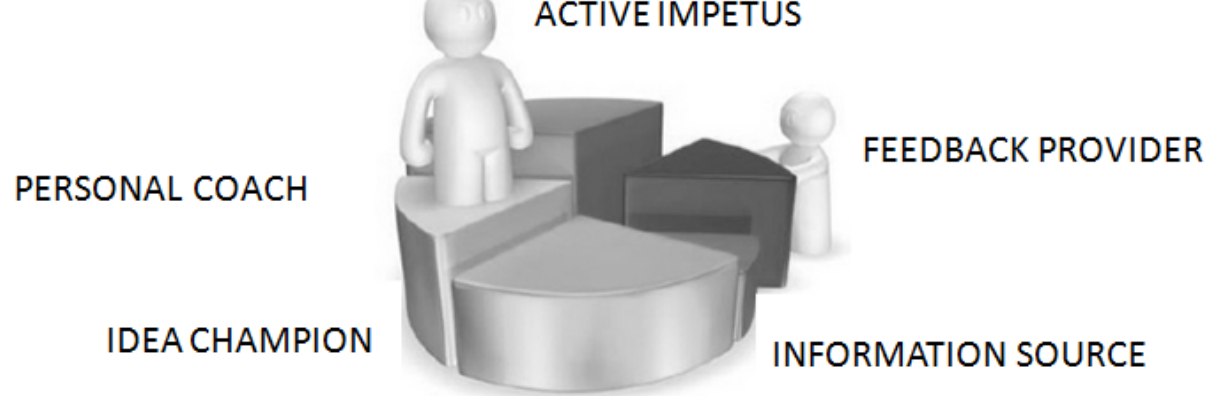

Fig. 1 Model of teachers' roles in ubiquitous learning space

Teachers' Role as Personal Coach in Ubiquitous Learning Space. The process of autonomous learning is a lengthy and complicated one, and more consultation and advice are desired by learners to overcome learning difficulties. Specifically speaking, teachers can offer learning strategies concerning many areas, for instance, from technical, psychological, socio-cultural to critical aspects of learners. The assistance given to learners should be in a customized and personalized way according to specific needs and various styles of learners. Besides, the concept of autonomy is inextricably linked to other advances in the learning environment such as technology and a new move towards ubiquitous learning. As a certain amount of new problems may pop out in the new mode of learning, more attention should be given to individual learners in the digital space. Particularly, learners are cultivated to acquire a complex of procedural skills that are developed only through use. Doors open as learners are navigating in ubiquitous learning space with appropriated guidelines and assistance from instructors.

Teachers' Role as Active Impetus in Ubiquitous Learning Space. It's obvious that autonomous learners must be interested and motivated in what they are doing. As the saying goes, "You can lead a horse to water, but you can't make it to drink". There will be no success in any form of learning without a motivated mind of the student in ubiquitous learning. Thus the teacher is required to play a motivating factor, making the learner willing to assume more responsibilities in learning process and proactively engage in the targeted material they are trying to learn. Incentive action plans about involving learners in interactive and cooperative activities ought to be executed by teachers. Rather than passing all responsibility to individual students it was more efficient to get students to work together, to collaborate with each other, and to pass responsibility onto groups of individuals. In ubiquitous learning space, the idea of teachers being active impetus is to introduce collaborative learning opportunities through the use of the wireless and mobile technologies with which students would learn together at any time and at any place.

Teachers' Role as Feedback Provider in Ubiquitous Learning Space. The feedback of learning can't be ignored when one argue how to make learning more reflective and constructive. Few things will make learners think over their learning process more than being provided with timely and supportive feedback from various agents (e.g. peer students, teachers, etc.) in ubiquitous learning space. Teachers are anticipated to facilitate learners' awareness of self-reflection through providing feedback to individual learners. Feedbacks from formative assessment and summative assessment in ubiquitous learning serve different functions and should be combined together to assist learners in developing a reflective and supportive learning environment. For the efficiency and efficacy of autonomous learning, it is the teacher who is expected to initiate the step to reflect on autonomous 
learning and find out a way that is more likely to be suited to their needs. Particularly, in ubiquitous learning space, teachers are supposed to make learners aware of the various techniques available to them for learning coupled with the ability to assess the success of these techniques.

Teachers' Role as Information Source in Ubiquitous Learning Space. The benefits of being autonomous learners may accrue from getting access to a wealth of information and reaching out for different people. In ubiquitous learning space, it's much easier than before. Nevertheless, it doesn't mean teachers are not desired by learners in this regard, but rather the teacher is one of important components behind learner autonomy in ubiquitous learning space, providing methods of seeking for high-quality information including both paper material and on-line one as required. Current trends of learning paradigm show huge potential for autonomous learning with the help of ubiquitous technologies. Through the use of pervasive technologies, learners are guided to explore more than textbook material. The learning is not expected to be confined to a fixed place or at certain time, and autonomy in learning involves learners taking more control of their learning, in and out of their classrooms, if not more learning done outside the classroom in student's own time than during classes. Teachers ought to provide learners with more assess to information in hope that learners can find their opportunities and potential on their own in ubiquitous learning space.

\section{Summary}

One can see that there is a global trend towards the incorporation of ubiquitous computing technologies generally in learning field with view to promoting learner autonomy. It's shown that roles teachers play in ubiquitous learning should shift accordingly. In ubiquitous learning, learners are anticipated to have less control on learning and more concern on learners. Concrete suggestions on teachers' roles are put forward regarding teachers as idea champion, personal coach, active impetus, feedback provider and information source in promoting learner autonomy based on ubiquitous computing technologies. It's hoped that the benefits of learner autonomy may accrue whilst teachers play appropriate and supportive roles in ubiquitous learning space.

\section{Acknowledgements}

This work is part of the project of On Cultivating and Developing Liaoning Scientific Foreign Language Talents with View to Bourdieu' Theory, the project of On Establishing Generative Mechanism of EFL Autonomous Learning Behaviors and Strengthening Development of Learning Field in Ubiquitous Learning Space, and the project of On Constructing Mechanism and Strategies for College English Autonomous Learning Abilities via Mobile Multimedia. This research was supported by the fund of Liaoning Planning of Philosophy and Social Science (Project No. L16CYY001), the fund of Liaoning Provincial Federation Social Science Circles (Project No. 2017lslktyb-019), and the fund of the Thirteenth Five-Year Plan of Education Sciences of Liaoning Province (Project No. JG16DB013).

\section{References}

[1] J. Piaget, \& B. Inhelder, The child's conception of space, New York, Norton,1967.

[2] H. Holec, Autonomy and foreign language learning, Oxford, Pergamon Press, 1981.

[3] Rodrigo, The concept of learning autonomy, The WritePass Journal, 2015.04.

[4] D. Nuan, Second language teaching and learning, Beijing, Foreign Language Teaching and Research Press, 2000.

[5] F. Edwords, http://infidels.org/library/modern/fred_edwords/humanism.html, 1989. 